\title{
Development of herbal molecules in treating autoimmune uveitis:
}

\section{a narrative review}

Justin CY Leung ${ }^{I^{*}}$, Austin ZX Tang ${ }^{1^{*}}$, BA (Cantab); Chun-Bon Wong ${ }^{{ }^{*}}$, Hei-Nga Wong ${ }^{l^{*}}$, Wai-Kit Chu ${ }^{2}$, DPhil

${ }^{1}$ Bachelor of Medicine and Bachelor of Surgery Programme, The Chinese University of Hong Kong, Hong Kong

${ }^{2}$ Department of Ophthalmology and Visual Sciences, Faculty of Medicine, The Chinese University of Hong, Hong Kong

* Equal contribution

Correspondence and reprint requests:

Wai-Kit Chu, Department of Ophthalmology and Visual Sciences, Faculty of Medicine, The Chinese University of Hong, Hong Kong.

Email:waikit@cuhk.edu.hk

\section{Abstract}

Current treatments for autoimmune uveitis involve the use of corticosteroids topically, locally (including subconjunctival, subtenon, orbital floor, and intraouclar injection), and systemically to attenuate the T cellmediated response by impairing cell trafficking and activation to the uvea and dampening cell response to ocular antigens. However, long-term local injection of corticosteroids may result in raised intraocular pressure, cataracts, and glaucoma. Systemic use of steroids may result in severe morbidity. Immunomodulatory agents and biologics can circumvent some of these issues but may result in other adverse effects. Herbal molecules are potentially useful in treatment of autoimmune uveitis. We review the literature about the pathogenesis of autoimmune uveitis and the mechanisms, efficacy, and safety of herbal molecules (curcumin, green tea, triptolide, caffeic acid phenethyl ester, total glucosides of peony, and Longdan Xiegan Tang) as a therapeutic option or supplement for autoimmune uveitis.

Key words: Caffeic acid phenethyl ester; Curcumin;

Epigallocatechin gallate; Longdan Xiegan Tang; Peony root extract; Triptolide; Uveitis

\section{Introduction}

Uveitis is the inflammation of the uvea that includes the iris, ciliary body, and vascular choroid. The damage from inflammation may extend to the sclera, vitreous, retina, and optic nerve. Uveitis mainly affects individuals aged 20 to 50 years and results in $5 \%$ to $10 \%$ of visual impairment worldwide, up to $25 \%$ of legal blindness cases in the developing world, and $5 \%$ to $20 \%$ of such cases in developed countries. ${ }^{1-4}$

Uveitis is classified based on the predominant anatomic site of inflammation (Table 1), clinical course (acute [ $<3$ months], chronic [ $>3$ months], and recurrent), laterality, etiology (infectious, non-infectious), and histopathological grading (granulomatous, non-granulomatous). ${ }^{5,6}$ These classifications have implications on the epidemiology, presentation, and management. Anterior uveitis is the most common (particularly the idiopathic form), followed by posterior uveitis, panuveitis, and intermediate uveitis., , $^{3,9}$ Rarely, uveitis may occur secondary to drug treatment for infections. ${ }^{10}$

Autoimmune uveitis (AU) or non-infectious uveitis is caused by a specific autoimmune response to retinal self-antigens or is a part of systemic autoimmune syndrome. ${ }^{11} 25 \%$ to $30 \%$ of uveitis cases are associated with a systemic autoimmune or autoinflammatory disease such as seronegative spondyloarthropathies (ankylosing spondylitis and psoriatic spondylitis). ${ }^{2,12}$ Uveitis occurs in $20 \%$ to $40 \%$ of ankylosing spondylitis cases and $7 \%$ to $16 \%$ of psoriatic spondylitis cases. $^{13,14}$ Other systemic diseases with manifestation to uveitis include sarcoidosis, juvenile idiopathic arthritis, Behcet disease, and Vogt-Koyanagi-Harada disease..$^{6.15 .16}$ Uveitis can also be caused by non-systemic diseases such as birdshot choroidopathy ${ }^{17}$ or as a complication of Mooren ulcer. ${ }^{18}$ In a Chinese population, idiopathic anterior uveitis, Vogt-Koyanagi-Harada disease, and Behcet disease are the most common etiologies for non-infectious uveitis..$^{8,19,20}$ 


\section{REVIEW ARTICLE}

\begin{tabular}{|c|c|c|}
\hline Type of uveitis & Major site of inflammation & Subset \\
\hline Anterior uveitis & Anterior chamber & $\begin{array}{l}\text { Iritis (affecting the iris) } \\
\text { Iridocyclitis (affecting the iris and ciliary body) } \\
\text { Anterior cyclitis (affecting the ciliary body) }\end{array}$ \\
\hline Intermediate uveitis & Vitreous & $\begin{array}{l}\text { Hyalitis/vitritis (affecting the vitreous cavity and/or pars plana) } \\
\text { Pars planitis (affecting the pars plana [obicularis ciliaris]) } \\
\text { Posterior cyclitis }\end{array}$ \\
\hline Posterior uveitis & Retina or choroid & $\begin{array}{l}\text { Retinitis (affecting the retina) } \\
\text { Choroiditis (affecting the choroid) } \\
\text { Retinochoroiditis/chorioretinitis (affecting the choroid and retina) } \\
\text { Neuroretinitis (affecting the optic disc) }\end{array}$ \\
\hline Panuveitis & Anterior chamber and vitreou & \\
\hline
\end{tabular}

Uveitis related to autoimmune disease is more common in developed countries; $70 \%$ to $90 \%$ of sight-threatening uveitis are reported to be non-infectious. ${ }^{2,15}$

\section{Autoimmune uveitis in mouse models}

The experimental AU mouse model is paramount in studying the pathogenesis of AU and efficacy of novel treatments. ${ }^{11,21}$ $\mathrm{AU}$ is induced by peripheral immunization through injection of evolutionarily conserved retinal antigens such as retinal soluble antigen, interphotoreceptor retinoid-binding protein (IRBP), and immunogenic peptide fragments of IRBP such as K2 (consisting of IRBP residues 201-216) ${ }^{22}$ and peptide 161-180 (used in the B10.RIII mouse strain). ${ }^{23}$ These antigens are emulsified in complete Freund adjuvant (comprising mineral oil and heat-killed mycobacterium tuberculosis). Susceptibility to each antigen depends on the animal strain; some strains require additional immune stimulation with pertussis toxin. ${ }^{24,25}$ Other methods of induction include adoptive transfer of uveitogen-specific lymphocytes and generation of transgenic mice that express IRBP-specific $\mathrm{T}$ cell receptors that spontaneously develop AU. The severity of AU can be assessed clinically (by fundoscopic examination) and histopathologically (by flow cytometry to assess severity and extent of inflammation, expression of cytokine and chemokine, and distribution of immune cells) ${ }^{26,27}$ However, these methods of assessment have shortcomings. ${ }^{28}$ Although fundus examination can assess retinal lesions and disease severity, it fails to determine cellular infiltration, retinal thickness, and visual function. Non-invasive methods are preferred so as to avoid disease progression secondary to excision. Optical coherence tomography enables real-time imaging of tissues in situ, revealing cellular infiltration, retinal thickness, and retinal lesions while correlating with fundus and histological grading. Electroretinography enables non-invasive and quantitative assessment of visual function and retinal response to light.

\section{Pathogenesis of experimental autoimmune uveitis}

A key player in pathogenesis of experimental AU is the transcription factor nuclear factor kappa-light-chain-enhancer of activated $\mathrm{B}$ cells $(\mathrm{NF}-\varkappa \mathrm{B})$, which regulates a multitude of genes that encode cytokines, chemokines, cell adhesion molecules, and molecules regulating cell survival. NF- $x \mathrm{~B}$ has a complex role in initiation, propagation, and resolution of inflammatory responses. ${ }^{29} \mathrm{NF}-\varkappa \mathrm{B}$ upregulates the expression of the pro-inflammatory cytokine such as tumor necrosis factor alpha $(\mathrm{TNF}-\alpha)$, which is mainly produced by macrophages and neutrophils. TNF- $\alpha$ plays a pivotal role in inflammation and experimental AU leading to tissue destruction (mediated by macrophages) and inducing pro-inflammatory cytokines interleukin (IL)-1 and IL-6. TNF- $\alpha$ is highly expressed in experimental AU models. ${ }^{30,31} \mathrm{NF}-\varkappa \mathrm{B}$ induces IL-12 and IL-23 expression from antigen-presenting cells that are essential in Th1 and Th17 polarization, respectively. ${ }^{32} \mathrm{TNF}-\alpha$ is a potent activator of $\mathrm{NF}-\varkappa \mathrm{B}$ and promotes inflammation via a positive feedback loop. ${ }^{33}$ Neutralizing TNF- $\alpha$ activity dampens interferon-gamma (IFN- $\gamma$ ) production, macrophage activity, and retention, as well as improves clinical and histological scores in experimental AU models..$^{30}$ Targeting TNF- $\alpha$ is the basis for successful immunomodulatory treatments for AU.In patients with Behcet disease with uveitis, inhibition of TNF- $\alpha$ using infliximab prevents Th17 differentiation and reduces expression of pro-inflammatory cytokines IFN- $\gamma$, IL-6, and IL-17 in ocular fluids. ${ }^{34}$ Therefore, NF- $x$ B, TNF- $\alpha$, IFN- $\gamma$, and pro-inflammatory cytokines such as IL-1, IL-6, and IL-17 are useful indicators for the efficacy of novel treatments in experimental AU models.

Th1 and Th17 cells are key to experimental AU models. The Th1 cells are induced by the cytokines IL-12 and IFN- $\gamma$. When activated, the Th1 cells produce both cytokines to orchestrate a cell-mediated (typically phagocyte-dependent) immune response. ${ }^{35}$ Specifically, IL-12 signaling phosphoactivates the STAT4 transcription factor that induces IFN- $\gamma$ production. ${ }^{36}$ Aberrant activation of Th1 can lead to an autoimmune response and induce experimental AU. ${ }^{37}$ However, IFN- $\gamma$ has paradoxical effects on experimental AU induction and disease course. In the long term, exposure to IFN- $\gamma$ exacerbates inflammation and damages retinal cells through potent activation of macrophages. ${ }^{38,39}$ In recent studies, the paradigm has shifted to the Th17 cells in experimental AU pathophysiology. 


\section{Medical treatments for autoimmune uveitis}

AU is primarily treated with corticosteroids; the administration route depends on the site of inflammation. Corticosteroids dampen the immune response by acting on intracellular glucocorticoid receptors to recruit deacetylases that transcriptionally silence proinflammatory genes. ${ }^{40}$ In early disease stage, topical prednisolone acetate $(1 \%)$ is usually used for anterior uveitis and localized periocular steroid injection (eg triamcinolone) for intermediate or posterior uveitis. ${ }^{16}$ Adverse effects include raised intraocular pressure, cataracts, glaucoma, and ptosis secondary to repeated injections. ${ }^{41}$ In cases resistant to initial treatment, immunosuppressive drugs such as methotrexate or cyclosporine are used. In experimental AU models, cyclosporine has shown to block calcineurin, which blocks the IL-2 signaling pathway to inhibit $\mathrm{T}$ cell development and prevent $\mathrm{T}$ cell differentiation into effector types. ${ }^{42}$ However, high-dose, long-term systemic steroid use can lead to Cushing syndrome ${ }^{20}$ and adverse effects in almost all organ systems. Immunomodulatory agents and biologics can circumvent some of these issues but may lead to other adverse effects. Biologic therapies involving TNF- $\alpha$ inhibitors such as adalimumab ${ }^{43}$ and infliximab ${ }^{44}$ are viable options.

\section{Herbal treatments}

Herbal compounds such as curcumin from turmeric (curcuma longa) and green tea extract (camellia sinensis) have ability to inhibit the disease process of AU. The effect of triptolide, caffeic acid phenethyl ester, total glucosides of peony, and Longdan Xiegan Tang on experimental AU has also been investigated (Table 2).

\section{Curcumin}

Curcumin is extracted from Curcuma longa (turmeric) and has been used for a wide array of purposes such as cosmetics, food conditioning, and medicine. Curcumin exhibits anti-inflammation and antioxidation properties by reducing proinflammatory factors and oxidative stress against ocular tissues. The mechanisms involve downregulating transcription factors and inflammatory mediators. ${ }^{45}$ Curcumin possesses the capacity to eliminate oxidative stress from reactive oxygen and nitrogen species and activate

Table 2. Beneficial and harmful effects, anti-inflammatory mechanisms, and effect on inflammatory cytokines of curcumin, green tea extract/ epigallocatechin gallate, triptolide, caffeic acid phenethyl ester, total glucosides of peony, and Longdan Xiegan Tang

\begin{tabular}{|c|c|c|c|c|}
\hline $\begin{array}{l}\text { Herbal } \\
\text { compound }\end{array}$ & Beneficial effects & Harmful effects & $\begin{array}{l}\text { Anti-inflammatory } \\
\text { mechanisms }\end{array}$ & $\begin{array}{l}\text { Effect on } \\
\text { inflammatory } \\
\text { cytokines }\end{array}$ \\
\hline Curcumin & $\begin{array}{l}\text { Anti-inflammation, antioxidation; } \\
\text { curcuminoids: short-term AU symptomatic } \\
\text { improvement, long-term relapses } \\
\text { prevention; curcumin capsule: reducing } \\
\text { the total number of patients with relapses } \\
\text { and the number of episodes of relapses in } \\
\text { individual patients; most sensitive toward } \\
\text { patients with autoimmune uveitis }\end{array}$ & $\begin{array}{l}\text { Gastric intolerance symptoms } \\
\text { ( } 0.8 \% \text { of cases), diarrhea, nausea, } \\
\text { rise in serum alkaline phosphatase } \\
\text { and lactic dehydrogenase, dose- } \\
\text { independent toxic effects (eg, } \\
\text { headache, yellow stool) }\end{array}$ & $\begin{array}{l}\text { Downregulating NF- } x \mathrm{~B} \text {, } \\
\text { STAT proteins (eg, STAT-4), } \\
\text { eliminating reactive oxygen } \\
\text { species and reactive nitrogen } \\
\text { species, activating endogenous } \\
\text { antioxidant defense (eg, } \\
\text { glutathione), and inhibiting } \\
\text { gelatinase B expression }\end{array}$ & $\begin{array}{l}\text { Downregulating IL-1, } \\
\text { IL-2, IL-6, IL-12 }\end{array}$ \\
\hline $\begin{array}{l}\text { Green tea } \\
\text { extract/ } \\
\text { epigallocat- } \\
\text { echin gallate }\end{array}$ & $\begin{array}{l}\text { Anti-inflammation and antioxidation, } \\
\text { improvement in clinical manifestation } \\
\text { and histopathological ocular damage by } \\
\text { alleviating retinal-choroidal edema, retinal } \\
\text { vasodilation, and visual impairment }\end{array}$ & $\begin{array}{l}\text { Well-tolerated in healthy } \\
\text { populations, no hepato-/nephro- } \\
\text { toxicity; contraindicated in } \\
\text { patients with renal failure or iron } \\
\text { deficiency anemia }\end{array}$ & $\begin{array}{l}\text { Downregulating NF- } x \mathrm{~B} \text { and } \\
\text { 20S/26S proteasome complex, } \\
\text { increasing Treg populations, } \\
\text { and decreasing Th1 and Th17 } \\
\text { populations }\end{array}$ & $\begin{array}{l}\text { Downregulating IL-1 } \beta \text {, } \\
\text { IL-6, IL-12, IL-17A, IL- } \\
23, \text { IFN- } \gamma \text {, and TNF- } \alpha \text {; } \\
\text { upregulating IL-10 }\end{array}$ \\
\hline Triptolide & $\begin{array}{l}\text { Improvement in histopathological score } \\
\text { (only before completion of T cell priming) }\end{array}$ & Not reported & $\begin{array}{l}\text { Downregulating Th1-mediated } \\
\text { inflammatory response, inhibiting } \\
\text { K2-mediated lymphocyte } \\
\text { proliferation (only before } \\
\text { completion of T cell priming) }\end{array}$ & $\begin{array}{l}\text { Downregulating IL-12, } \\
\text { IFN- } \gamma \text {, and TNF- } \alpha\end{array}$ \\
\hline $\begin{array}{l}\text { Caffeic acid } \\
\text { phenethyl } \\
\text { ester }\end{array}$ & $\begin{array}{l}\text { Anti-inflammation, immunomodulation; } \\
\text { histopathological improvement by reducing } \\
\text { amount of focal linear lesion, severity of } \\
\text { vasculitis, retinal fold, and inflammatory } \\
\text { infiltrate; no detrimental effect on } \\
\text { hematopoiesis or liver and renal functions }\end{array}$ & $\begin{array}{l}\text { High affinity for albumin leading } \\
\text { to herb-drug interactions }\end{array}$ & $\begin{array}{l}\text { Downregulating } \mathrm{NF}-\varkappa \mathrm{B} \text {, } \\
\text { inhibiting } \mathrm{T} \text { cell proliferation }\end{array}$ & $\begin{array}{l}\text { Downregulating IL-6, } \\
\text { TNF- } \alpha, \text { MIP-1 } \beta \text {, and } \\
\text { RANTES }\end{array}$ \\
\hline $\begin{array}{l}\text { Total } \\
\text { glucosides } \\
\text { of peony }\end{array}$ & $\begin{array}{l}\text { Anti-inflammation, antioxidation, } \\
\text { immunomodulation, and analgesic; } \\
\text { improvement in clinical score (fundus } \\
\text { examination) }\end{array}$ & Not reported & $\begin{array}{l}\text { Downregulating MAPK, } \\
\text { reducing CD4+, CD4+/CD8+, } \\
\text { and IFN- } \gamma \text {, and increasing CD } 8+ \\
\text { cells }\end{array}$ & $\begin{array}{l}\text { Downregulating IL- } 1 \beta \text {, } \\
\text { IL-6, IL-17A, TNF- } \alpha \text {, } \\
\text { MCP-1, and RANTES }\end{array}$ \\
\hline
\end{tabular}


endogenous antioxidant defense including glutathione. ${ }^{46}$ Curcumin inhibits gelatinase $\mathrm{B}$ expression and thus reduces angiogenesis in inflammation. ${ }^{47}$

In a study of corticosteroid use adjunct with curcuminoids (curcumin dietary supplement) for recurrent uveitis, ${ }^{48}$ 122 patients with up to four relapses annually who had been followed up for 2 years were recruited for a 1-year observation. Curcuminoids was started once the patients had a new relapse. 15 patients were excluded owing to non-compliance. One patient developed gastric intolerance symptoms. In the remaining 106 (61 male and 45 female) patients who had relapses before intervention, only 19 had relapses after taking curcuminoids, which is an $80 \%$ decrease $(\mathrm{p}<0.001) .275$ episodes of relapses were observed before intervention, but only 36 episodes were observed at the end of the intervention, which is an $87 \%$ decrease $(\mathrm{p}<0.001)$. Patients with recurrent AU were the most benefited from the intervention. Therefore, curcumin is considered a bioactive well-tolerated non-toxic therapy.

In a study of 32 patients with chronic anterior uveitis, 18 received curcumin alone $(n=18)$ and 14 who had a reaction to paraphenylenediamine received curcumin in addition to antitubercular treatment. ${ }^{49}$ Curcumin capsules were given three times a day and were followed up for 3 years. Outcome measures were symptomatic improvement and recurrence rate. After 2 weeks of intervention, $100 \%$ and $86 \%$ of patients in the respective groups showed symptomatic improvement. Over the 3-year follow-up, the recurrence rate was 55\% and $36 \%$ in the respective groups. No patient developed any adverse effects. These results suggest that curcumin is useful in short-term symptom alleviation and long-term relapse prevention.

Curcumin has shown positive treatment efficacy in anterior segment eye diseases including conjunctivitis secondary to immunological responses. ${ }^{50}$ However, in the perspective of chemistry and pharmacy, curcumin is considered a pan-assay interference compound and invalid metabolic panaceas, thereby leading to false treatment efficacy. ${ }^{51}$ In addition, curcumin is not a good drug candidate owing to its poor pharmacokinetics and limited bioavailability. Nonetheless, curcumin has shown efficacy in clinical and in vivo studies (non-placebo- and placebo-controlled). ${ }^{48,49,52}$ Therefore, advancement in knowledge today should not overthrow findings of previous curcumin studies. ${ }^{52}$

In a study of 25 patients with advanced pancreatic cancer who received $8 \mathrm{~g}$ of oral curcumin daily until disease progression, no treatment-related toxic effects were found in 24 patients despite extensive toxic monitoring including complete history taking, physical examination, blood tests (complete blood count, renal and liver function test), and diagnostic imaging. ${ }^{53}$ In a study of 38 healthy individuals aged 40 to 60 years who received either $80 \mathrm{mg}$ of curcumin daily or placebo for 4 weeks, curcumin resulted in lowering of plasma triglycerides and beta amyloid levels. ${ }^{54}$ In contrast, in a study of 15 patients with advanced colorectal cancer who received curcumin $0.45 \mathrm{~g}$ to $3.6 \mathrm{~g}$ daily up to 4 months, two patients (who consumed $0.45 \mathrm{~g}$ and $0.9 \mathrm{~g}$ curcumin) had diarrhea after 1 and 4 months of treatment, respectively. ${ }^{55}$ One patient (who consumed $0.9 \mathrm{~g}$ curcumin) experienced nausea, which resolved spontaneously. Four and three patients had a rise in serum alkaline phosphatase level and serum lactate dehydrogenase level, respectively. In a study of 24 healthy individuals who received escalation doses of 500 to $12000 \mathrm{mg}$ curcumin, seven individuals experienced dose-independent toxic effects such as headache and yellow stool. ${ }^{56}$ Therefore, toxicity of curcumin should be further investigated.

\section{Green tea}

Green tea is isolated from Camellia sinensis; its three main components namely caffeine, essential oils, and polyphenolic compounds such as catechins have beneficial health effects. ${ }^{57}$ Green tea extract and its main component epigallocatechin gallate (EGCG) have shown favorable results in laboratory trials. EGCG alters naive $\mathrm{CD}^{+}{ }^{+} \mathrm{T}$ cell differentiation and slows down Th1 and Th17 differentiation and thus prevent the induction of IL- $6 .{ }^{58}$ Green tea extract has protective effect on intraocular infectious inflammation..$^{59}$

In a murine study to investigate the effect of green tea extract and EGCG on intraocular autoimmune inflammation, ${ }^{60}$ mice were randomly allocated into 12 groups, including different dosages of green tea extract and EGCG, dexamethasone (as positive control), and water (as negative control). Outcome measures were retinal-choroidal thickness, major retinal vessel diameter, and electroretinography amplitudes. Results suggested that green tea extract, but not EGCG alone, could be a potential anti-inflammatory agent against AU (Table 2). Less significant changes in EGCG-alone treatments may be because EGCG has poor pharmacokinetic properties or other components of green tea extract may play a role. Green tea extract and EGCG are likely to be well tolerated drugs in healthy populations. ${ }^{60}$ There were no steroid-induced adverse effects such as hepatotoxicity or nephrotoxicity. Nonetheless, the presence of aluminum in green tea should be contraindicated in patients with renal failure, as a decrease in aluminum excretion may cause neurological symptoms. ${ }^{57}$ The high affinity of green tea catechins for iron should be aware to prevent aggregation of symptoms in patients with iron deficiency anemia. In addition, green tea contains caffeine and may cause palpitations, which may be alleviated by extracting only the essence of green tea.

\section{Triptolide}

Triptolide (TRD) is a major active ingredient of Tripterygium wilfordii Hook F. It has shown lymphocyte proliferation and lymphocyte reaction inhibition effects on suppressing K2-induced experimental AU. ${ }^{61}$ Mice with experimental AU were treated with phosphate buffer saline (control), cyclosporine (positive control), TRD-whole period (from days 0-28), or TRD-efferent period (from days 14-28) after immunization. Outcome measures were histopathological scoring of experimental AU, extent of lymphocyte proliferation, Th1-type cytokine mRNA expression, and percentage of apoptosis in $\mathrm{CD}^{+} \mathrm{T}$ cells. Results showed 
that the histopathological score was similar between the cyclosporine group and the TRD-whole period group. Both groups were able to inhibit K2-mediated lymphocyte proliferation and to decrease Th1-type cytokine mRNA expression (IFN-y, IL-12p40, TNF- $\alpha$ ). However, the TRDefferent period group developed AU. TRD has a cytotoxic effect on tumor cells of hematological malignancies. The percentage of apoptotic CD4 ${ }^{+} \mathrm{T}$ cells between TRD-treated and-untreated groups was similar. This excludes the possibility of TRD-mediated cytotoxicity in which experimental AU is eliminated through Th1 cell apoptosis. Thus, TRD is only effective when the treatment is given before T-cell priming; it has a protective effect on experimental AU induction.

\section{Caffeic acid phenethyl ester}

A murine study investigated the effect of caffeic acid phenethyl ester (CAPE), a phenolic compound extracted from honeybee propolis, on AU. ${ }^{62}$ CAPE was reported to have anti-inflammatory, and immunomodulatory properties. ${ }^{63}$ The mechanism of CAPE was to specifically inhibit NF- $x \mathrm{~B}$ activity by preventing its translocation into the nucleus. ${ }^{64} \mathrm{CAPE}$ alleviated the severity of AU in mice. Histological findings showed fewer focal linear lesions and milder vasculitis when CAPE was administered. Also, there was a reduction of retinal fold and less inflammatory infiltrate on the retina of CAPE-treated mice, compared with vehicle-treated mice. These results indicate that CAPE can suppress the ocular inflammatory response and preserve retinal structure in mice with AU. CAPE could reduce proinflammatory molecules. Flow cytometry showed lower levels of TNF- $\alpha$, IL- 6 , and IFN- $\gamma$ in CAPE-treated mice, compared with vehicle-treated mice. This is likely attributed to CAPE's effect on inhibiting the NF- $x \mathrm{~B}$ pathway. CAPEtreated mice showed a significant decrease in the expression of MIP-1 $\beta$ and RANTES. MIP- $1 \beta$ is a potent chemoattractant of macrophages and T lymphocytes. RANTES aggravates the progression of endogenous posterior uveitis. IFN- $\gamma$ can work synergistically with TNF- $\alpha$ to increase RANTES production by retinal pigment epithelial cells.$^{65} \mathrm{CAPE}$ is incapable of suppressing T-cell proliferation. IRBP-specific T cells in the spleens and lymph nodes were evaluated; the proliferation rate of $\mathrm{CD}^{+}{ }^{+}$was similar between CAPE-treated and vehicletreated groups. In terms of pharmacokinetics, CAPE has a strong ability to bind to human serum albumin by static quenching. ${ }^{66}$ The CAPE-albumin complex can be a reservoir that can prolong its half-life and enhance bioavailability. However, this poses a risk of herb-drug interactions if the patient is taking other drugs that have high affinity for albumin, and the concentration of CAPE and other drugs will be unpredictable. The CAPE delivery system showed no sign of toxicity. ${ }^{67} \mathrm{CAPE}$ has no detrimental effect on hematopoiesis or liver and renal function. Hence, CAPE is a non-toxic copolymer.

\section{Total glucosides of peony}

A murine experiment investigated the effects of total glucosides of peony (TGP), which is extracted from the roots of Paeonia lactiflora Pall, on suppressing experimental AU. ${ }^{68}$ TGP showed anti-inflammatory and immunomodulatory effects. Nine female C75BL/6 mice with or without experimental AU were randomly allocated into three groups: sham (no AU and no treatment), control (AU and saline treatment), and TGP (AU and TGP treatment). Outcome measures were clinical scoring of the fundus image, measurement of the concentration of inflammatory markers, flow cytometry, and western blot. Fundus measurements on days 14,21 , and 28 revealed a higher score in the control than TGP group. This indicates the ability of TGP in suppressing experimental AU-associated inflammation. The concentrations of proinflammatory cytokines (IL-1 $\beta$, IL-6, TNF- $\alpha$ ), chemokines (MCP-1, RANTES), and Th17 cytokine IL-17A decreased in the intraocular fluid of the TGP group. Flow cytometry showed that TGP suppressed CD4+ and IFN- $\gamma$ populations while increasing CD8+ populations. This finding is in line with other molecular studies that show that a decrease in Th1 cells alleviates symptoms of AU. Western blot analysis revealed a significant decrease in phosphorylation of p38, extracellular-activated kinase, and c-Jun-N-terminal kinase. This indicates the anti-inflammatory effect of TGP by suppressing the MAPK signaling pathway. Thus, TGP has remarkable results on autoimmune diseases such as rheumatoid arthritis. However, the finding of inhibition of both Th1 and Th 2 cell function in suppressing AU contradicts with the traditional mechanism that only Th1 and Th17 cause intraocular inflammation.

\section{Longdan Xiegan Tang}

Longdan Xiegan Tang (LXT) is a mixture of 10 herbal extracts including Radix Gentianae, Radix Scutellariae, Fructus Gardeniae, Rhizoma Alismatis, Caulis Clematidis Armandii, Semen Plantaginis, Radix Angelicae Sinensis, Radix Rehmanniae, Radix Bupleuri, and Radix Glycyrrhizae. LXThas anti-inflammatory, anti-allergy, and hepatoprotectant activities. In a study of the effect of LXT on treating rats with experimental $\mathrm{AU}{ }^{69}$ rats were divided into three groups: normal control (that received sterilized distilled water), experimental AU (via injection of IRBP1177-1191 emulsion), and LXT treatment (oral gavage of $200 \mathrm{mg} / \mathrm{kg}$ / day). LXT showed a high efficacy of alleviating symptoms of AU. LXT significantly reduced the inflammatory response of the anterior segment. Retinal camera and histological findings showed less severe fibrin exudate and obscured pupils after LXT treatment. Red reflex was detected in the LXT group but not in the experimental AU group. The LXT group had decreased inflammatory infiltration and fibrin exudation in anterior chamber, reduced synechia of the iris and ciliary body structure disorder, mild-to-moderate inflammation of the retina, and photoreceptor outer segment damage or lesions extending to the outer nuclear layer. The LXT group recovered at a faster rate than the experimental AU, particularly from days 14 to 18 . Flow cytometry showed that the ratio of $\mathrm{CD}^{+} / \mathrm{CD}^{+}$in lymph nodes and spleen reduced on days 12 and 16. This indicates a reduced immune response. However, there was no significant difference in $\mathrm{CD}^{+}$and $\mathrm{CD}^{+}$levels on days 12 and 16. Peak levels of IFN- $\gamma, \mathrm{IL}-17$, and TNF- $\alpha$ pro-inflammatory cytokines were lower in the LXT group than the experimental AU group, particularly on days 8,12 , and 16 . For IL-10, an anti-inflammatory cytokine, 
was markedly elevated on days 12,16 , and 20 . This indicates that LXT can suppress the inflammatory response by altering the production of different cytokines. In terms of safety, LXT contains Radix bupleuri that increases the risk of liver injury in patients infected with hepatitis $\mathrm{B}$ virus. ${ }^{70}$ The harmful effect of LXT is correlated with the cumulative dose of Radix bupleuri. Bupleurum might be a source of hepatotoxicity.

\section{Conclusion}

Curcumin has potentials for treating AU. It improves symptoms and minimize relapses of AU. Green tea extract and EGCG have positive results in mice by reducing both clinical and histopathological scores and suppressing the relevant autoimmune $\mathrm{T}$ cell responses. They have anti-inflammatory activity and can dampen Th1 and Th17 responses. Nonetheless, patients at risk of iron deficiency anemia or renal failure are contraindicated. TRD, CAPE, TGP, and LXT may improve experimental AU by reducing inflammatory cytokine levels and minimizing clinical scores. TRD is effective only at the time of disease induction and therefore may not achieve similar efficacy in humans. AU is a complex disease with numerous underlying systemic pathologies. Exploring the potentials for a synergistic relationship between herbal drugs and current medical treatments may reduce the adverse effects of immunosuppression by reducing the dosages of corticosteroids.

\section{Contributors}

All authors designed the study, acquired the data, analyzed the data, drafted the manuscript, and critically revised the manuscript for important intellectual content. All authors had full access to the data, contributed to the study, approved the final version for publication, and take responsibility for its accuracy and integrity.

\section{Conflict of interest}

All authors have disclosed no conflicts of interest.

\section{Funding/support}

This study received no specific grant from any funding agency in the public, commercial, or not-for-profit sectors.

\section{Data availability}

All data generated or analyzed during the present study are available from the corresponding author on reasonable request.

\section{References}

1. Nussenblatt RB. The natural history of uveitis. Int Ophthalmol 1990;14:303-8. crossref

2. Bodaghi B, Cassoux N, Wechsler B, et al. Chronic severe uveitis: etiology and visual outcome in 927 patients from a single center. Medicine (Baltimore) 2001;80:263-70. Crossref

3. Miserocchi E, Fogliato G, Modorati G, Bandello F. Review on the worldwide epidemiology of uveitis. Eur J Ophthalmol 2013;23:705-17. crossref

4. Tsirouki T, Dastiridou A, Symeonidis C, et al. A focus on the epidemiology of uveitis. Ocul Immunol Inflamm 2018;26:216. Crossref

5. Bloch-Michel E, Nussenblatt RB. International Uveitis Study Group recommendations for the evaluation of intraocular inflammatory disease. Am J Ophthalmol 1987;103:234-5. Crossref

6. Jabs DA, Nussenblatt RB, Rosenbaum JT, Standardization of Uveitis Nomenclature Working G. Standardization of uveitis nomenclature for reporting clinical data. Results of the First International Workshop. Am J Ophthalmol 2005;140:50916. Crossref

7. Hwang DK, Chou YJ, Pu CY, Chou P. Epidemiology of uveitis among the Chinese population in Taiwan: a population-based study. Ophthalmology 2012;119:2371-6. Crossref

8. Yang $P$, Zhang Z, Zhou H, et al. Clinical patterns and characteristics of uveitis in a tertiary center for uveitis in China. Curr Eye Res 2005;30:943-8. Crossref

9. McCannel CA, Holland GN, Helm CJ, Cornell PJ, Winston JV, Rimmer TG. Causes of uveitis in the general practice of ophthalmology. UCLA Community-Based Uveitis Study Group. Am J Ophthalmol 1996;121:35-46. Crossref

10. Shafran SD, Deschenes J, Miller M, Phillips P, Toma E. Uveitis and pseudojaundice during a regimen of clarithromycin, rifabutin, and ethambutol. MAC Study Group of the Canadian HIV Trials Network. N Engl J Med 1994;330:438-9. Crossref

11. Caspi RR. Understanding autoimmune uveitis through animal models. The Friedenwald Lecture. Invest Ophthalmol Vis Sci 2011;52:1872-9. Crossref

12. Rothova A, Buitenhuis HJ, Meenken C, et al. Uveitis and systemic disease. Br J Ophthalmol 1992;76:137-41. Crossref

13. Edmunds L, Elswood J, Calin A. New light on uveitis in ankylosing spondylitis. J Rheumatol 1991;18:50-2.

14. Banares A, Hernandez-Garcia C, Fernandez-Gutierrez B, Jover JA. Eye involvement in the spondyloarthropathies. Rheum Dis Clin North Am 1998;24:771-84. Crossref

15. Lee RW, Nicholson LB, Sen HN, et al. Autoimmune and autoinflammatory mechanisms in uveitis. Semin Immunopathol 2014;36:581-94. Crossref

16. Rosenbaum JT, Bodaghi B, Couto C, et al. New observations and emerging ideas in diagnosis and management of non-infectious uveitis: a review. Semin Arthritis Rheum 2019;49:438-45. Crossref

17. Kiss S, Anzaar F, Stephen Foster C. Birdshot retinochoroidopathy. Int Ophthalmol Clin 2006;46:39-55. Crossref

18. Chen J, Xie H, Wang Z, et al. Mooren's ulcer in China: a study of clinical characteristics and treatment. Br J Ophthalmol 2000;84:1244-9. crossref

19. Chung YM, Yeh TS, Liu JH. Endogenous uveitis in Chinese: an analysis of 240 cases in a uveitis clinic. Jpn J Ophthalmol 1988;32:64-9.

20. Ng D, Mohamed S, Chu WK, Luk FO, Brelen M, Chan CKM. Update on uveitis management. Hong Kong J Ophthalmol 2016;20:95. 
21. Bansal S, Barathi VA, Iwata D, Agrawal R. Experimental autoimmune uveitis and other animal models of uveitis: An update. Indian J Ophthalmol 2015;63:211-8. Crossref

22. Namba K, Ogasawara K, Kitaichi $N$, et al. Identification of a peptide inducing experimental autoimmune uveoretinitis (EAU) in H-2Ak-carrying mice. Clin Exp Immunol 1998;111:4429. Crossref

23. Silver PB, Rizzo LV, Chan CC, Donoso LA, Wiggert B, Caspi RR. Identification of a major pathogenic epitope in the human IRBP molecule recognized by mice of the $H$-2r haplotype. Invest Ophthalmol Vis Sci 1995;36:946-54.

24. Silver PB, Chan CC, Wiggert B, Caspi RR. The requirement for pertussis to induce EAU is strain-dependent: B10.RIII, but not B10.A mice, develop EAU and Th1 responses to IRBP without pertussis treatment. Invest Ophthalmol Vis Sci 1999;40:2898905.

25. Caspi RR, Chan CC, Leake WC, Higuchi M, Wiggert B, Chader GJ. Experimental autoimmune uveoretinitis in mice. Induction by a single eliciting event and dependence on quantitative parameters of immunization. J Autoimmun 1990;3:237-46. Crossref

26. Caspi R.Autoimmunity in the immune privileged eye:pathogenic and regulatory T cells. Immunol Res 2008;42:41-50. Crossref

27. Agarwal RK, Silver PB, Caspi RR.Rodent models of experimental autoimmune uveitis. Methods Mol Biol 2012;900:443-69. Crossref

28. Chen J, Caspi RR. Clinical and functional evaluation of ocular inflammatory disease using the model of experimental autoimmune uveitis. Methods Mol Biol 2019;1899:21127. crossref

29. Hayden MS, Ghosh S. NF-kappaB in immunobiology. Cell Res 2011;21:223-44. Crossref

30. DickAD, Forrester JV, Liversidge J, Cope AP. The role of tumour necrosis factor (TNF-alpha) in experimental autoimmune uveoretinitis (EAU).Prog Retin Eye Res 2004;23:617-37. Crossref

31. OkadaAA, Keino H, Fukai T, Sakai J, Usui M, Mizuguchi J.Effect of type I interferon on experimental autoimmune uveoretinitis in rats. Ocul Immunol Inflamm 1998;6:215-26. Crossref

32. Croxford AL, Kulig P, Becher B. IL-12-and IL-23 in health and disease. Cytokine Growth Factor Rev 2014;25:415-21. Crossref

33. Taniguchi $K$, Karin M. NF-kappaB, inflammation, immunity and cancer: coming of age. Nat Rev Immunol 2018;18:30924. Crossref

34. Sugita S, Kawazoe Y, Imai A, Yamada Y, Horie S, Mochizuki M. Inhibition of Th17 differentiation by anti-TNF-alpha therapy in uveitis patients with Behcet's disease. Arthritis Res Ther 2012;14:R99. Crossref

35. Mosmann TR, Coffman RL.TH1 and TH2 cells: different patterns of lymphokine secretion lead to different functional properties. Annu Rev Immunol 1989;7:145-73. Crossref

36. Morinobu A, Gadina M, Strober W, et al. STAT4 serine phosphorylation is critical for IL-12-induced IFN-gamma production but not for cell proliferation. Proc Natl Acad Sci U S A 2002;99:12281-6. Crossref

37. Caspi RR, Silver PB, Chan CC, et al. Genetic susceptibility to experimental autoimmune uveoretinitis in the rat is associated with an elevated Th1 response. J Immunol 1996;157:2668-75.

38. Egwuagu CE, Mahdi RM, Chan CC, et al. Expression of interferon-gamma in the lens exacerbates anterior uveitis and induces retinal degenerative changes in transgenic Lewis rats. Clin Immunol 1999;91:196-205. Crossref

39. Forrester JV, Huitinga I, Lumsden L, Dijkstra CD. Marrowderived activated macrophages are required during the effector phase of experimental autoimmune uveoretinitis in rats. Curr Eye Res 1998;17:426-37. crossref

40. Barnes PJ.How corticosteroids control inflammation: Quintiles
Prize Lecture 2005. Br J Pharmacol 2006;148:245-54. Crossref

41. Sen HN, Vitale S, Gangaputra SS, et al.Periocular corticosteroid injections in uveitis: effects and complications. Ophthalmology 2014;121:2275-86. Crossref

42. Nussenblatt RB, Dinning WJ, Fujikawa LS, Chan CC, Palestine AG. Local cyclosporine therapy for experimental autoimmune uveitis in rats. Arch Ophthalmol 1985;103:155962. Crossref

43. LaMattina KC, Goldstein DA. Adalimumab for the treatment of uveitis. Expert Rev Clin Immunol 2017;13:181-8. Crossref

44. Khalili H, Lee RW, Khaw PT, Brocchini S, Dick AD, Copland DA. An anti-TNF-alpha antibody mimetic to treat ocular inflammation. Sci Rep 2016;6:36905. Crossref

45. Gupta SC, Patchva S, Koh W, Aggarwal BB. Discovery of curcumin, a component of golden spice, and its miraculous biological activities. Clin Exp Pharmacol Physiol 2012;39:28399. Crossref

46. Radomska-Lesniewska DM, Osiecka-Iwan A, Hyc A, Gozdz, A, Dabrowska AM, Skopinski P.Therapeutic potential of curcumin in eye diseases. Cent Eur J Immunol 2019;44:181-9. Crossref

47. Mohan R, Sivak J, Ashton P, et al. Curcuminoids inhibit the angiogenic response stimulated by fibroblast growth factor-2, including expression of matrix metalloproteinase gelatinase $B$. J Biol Chem 2000;275:10405-12. Crossref

48. Allegri P, Mastromarino A, Neri P. Management of chronic anterior uveitis relapses: efficacy of oral phospholipidic curcumin treatment. Long-term follow-up. Clin Ophthalmol 2010;4:1201-6. Crossref

49. Lal B, Kapoor AK, Asthana OP, et al. Efficacy of curcumin in the management of chronic anterior uveitis. Phytother Res 1999;13:318-22. Crossref

50. Liu XF, Hao JL, Xie T, et al. Curcumin, A potential therapeutic candidate for anterior segment eye diseases: a review. Front Pharmacol 2017;8:66. Crossref

51. Nelson KM, Dahlin JL, Bisson J, Graham J, Pauli GF, Walters MA. The essential medicinal chemistry of curcumin. $J$ Med Chem 2017;60:1620-37. Crossref

52. Heger M. Drug screening: Don't discount all curcumin trial data. Nature 2017;543:40. Crossref

53. Dhillon N, Aggarwal BB, Newman RA, et al. Phase II trial of curcumin in patients with advanced pancreatic cancer. Clin Cancer Res 2008;14:4491-9. Crossref

54. DiSilvestro RA, Joseph E, Zhao S, Bomser J. Diverse effects of a low dose supplement of lipidated curcumin in healthy middle aged people. Nutr J 2012;11:79. Crossref

55. Sharma RA, Euden SA, Platton SL, et al. Phase I clinical trial of oral curcumin: biomarkers of systemic activity and compliance. Clin Cancer Res 2004;10:6847-54. Crossref

56. Lao CD, Ruffin MTt, Normolle D, et al. Dose escalation of a curcuminoid formulation. BMC Complement Altern Med 2006;6:10. crossref

57. Cabrera $C$, Artacho R, Gimenez R. Beneficial effects of green tea--a review. J Am Coll Nutr 2006;25:79-99. Crossref

58. Wu D, Wang J, Pae M, Meydani SN. Green tea EGCG, T cells, and T cell-mediated autoimmune diseases. Mol Aspects Med 2012;33:107-18. Crossref

59. Qin YJ, Chu KO, Yip YW, et al. Green tea extract treatment alleviates ocular inflammation in a rat model of endotoxininduced uveitis. PLoS One 2014;9:e103995. Crossref

60. Li J, Yip YWY, Ren J, et al. Green tea catechins alleviate autoimmune symptoms and visual impairment in a murine model for human chronic intraocular inflammation by inhibiting Th17-associated pro-inflammatory gene expression. Sci Rep 2019;9:2301. Crossret

61. Wu Y, Wang Y, Zhong C, Li Y, Li X, Sun B. The suppressive 


\section{REVIEW ARTICLE}

effect of triptolide on experimental autoimmune uveoretinitis by down-regulating Th1-type response. Int Immunopharmacol 2003;3:1457-65. Crossref

62. Choi JH, Roh $\mathrm{KH}, \mathrm{Oh} \mathrm{H}$, et al. Caffeic acid phenethyl ester lessens disease symptoms in an experimental autoimmune uveoretinitis mouse model.Exp Eye Res 2015;134:53-62. Crossref

63. Armutcu F, Akyol S, Ustunsoy S, Turan FF. Therapeutic potential of caffeic acid phenethyl ester and its anti-inflammatory and immunomodulatory effects (Review). Exp Ther Med 2015;9:1582-8. crossref

64. Natarajan K, Singh S, Burke TR Jr, Grunberger D, Aggarwal BB. Caffeic acid phenethyl ester is a potent and specific inhibitor of activation of nuclear transcription factor NF-kappa B. Proc Natl Acad Sci U S A 1996;93:9090-5. Crossref

65. Crane IJ, Kuppner MC, McKillop-Smith S, Knott RM, Forrester JV. Cytokine regulation of RANTES production by human retinal pigment epithelial cells. Cell Immunol 1998; 184:37-44. Crossref

66. Li H, Wu F, Tan J, et al. Caffeic acid phenethyl ester exhibiting distinctive binding interaction with human serum albumin implies the pharmacokinetic basis of propolis bioactive components. $J$ Pharm Biomed Anal 2016;122:21-8. Crossref

67. Yordanov $Y$, Aluani D, Tzankova $V$, et al. Safety assessment of a newly synthesized copolymer for micellar delivery of hydrophobic caffeic acid phenethyl ester. Pharm Dev Technol 2020;25:1271-80. Crossref

68. Huang XT, Wang B, Zhang WH, Peng MQ, Lin D.Total glucosides of paeony suppresses experimental autoimmune uveitis in association with inhibition of Th1 and Th2 cell function in mice. Int J Immunopathol Pharmacol 2018;32:394632017751547. crossref

69. Tang $K$, Guo $D$, Zhang L, et al. Immunomodulatory effects of Longdan Xiegan Tang on CD4+/CD8+ T cells and associated inflammatory cytokines in rats with experimental autoimmune uveitis. Mol Med Rep 2016;14:2746-54. Crossref

70. Lee CH, Wang JD, Chen PC. Risk of liver injury associated with Chinese herbal products containing radix bupleuri in 639,779 patients with hepatitis B virus infection. PLoS One 2011;6:e16064. crossret 